\title{
Non-aneurysmal Subarachnoid Hemorrhage Associated with Basilar Artery Dissection
}

\author{
-Autopsy Case Report-
}

\author{
Tsuneaki OGIICHI, Shunro ENDO, Keiichiro OnIZUKA, Michiyasu TAKABA, \\ Akira TAKAKU, and Masanori YASUDA*
}

\author{
Departments of Neurosurgery and *Pathology, Toyama Medical and \\ Pharmaceutical University, Toyama
}

\begin{abstract}
A 60-year-old male presented with subarachnoid hemorrhage (SAH) of unknown origin and died of peritonitis 2 months after the ictus. Computed tomography on admission revealed localized hemorrhage at the interpedunclar cistern and sedimentation in both posterior horns. Repeat angiography could not detect any aneurysm. Postmortem histological examination revealed disruption of the wall associated with intramural hemorrhage at the top of the basilar artery, and subintimal hemorrhages of the lower basilar artery and the left vertebral artery. Arterial dissection of the vertebrobasilar system may be a cause of SAH of unknown origin including perimesencephalic hemorrhage.
\end{abstract}

Key words: perimesencephalic hemorrhage, dissection, basilar artery, pathology

\section{Introduction}

Four-vessel angiography detects no aneurysm in $15 \%$ to $20 \%$ of patients with spontaneous subarachnoid hemorrhage $(\mathrm{SAH})^{8]}$ and two-thirds of these patients have a perimesencephalic pattern of hemorrhage. ${ }^{4,5.14,16)}$ Perimesencephalic hemorrhage is a non-aneurysmal and benign form of $\mathrm{SAH}$ detected by early computed tomography (CT). The cause of this type of SAH is obscure, because the outcome is generally good and no postmortem studies have been conducted. ${ }^{1,7,9-14)}$ On the other hand, dissecting aneurysm, especially of the vertebrobasilar system, is one cause of SAH of unknown origin. ${ }^{11)}$ We report an autopsy case with vertebrobasilar artery dissection and discuss the cause of unknown origin SAH including perimesencephalic hemorrhage.

\section{Case Report}

A 60-year-old male presented with a 4-day history of gradually progressive headache and subsequent vomiting followed by loss of consciousness on June 24, 1992. On admission, his Glasgow Coma Scale

Received December 5, 1996; Accepted March 25, 1997 score was 7 (E1, V1, M5). After admission, he recovered consciousness, and mild dysphagia and left pharyngeal hyporeflexia were observed.

CT revealed localized hemorrhage in the interpeduncular cistern and sedimentation in both posterior horns, as well as bilateral ventricular dilatation (Fig. 1). Cerebral angiography demonstrated wall irregularity of the left vertebral artery (VA) and basilar artery (BA), but no apparent vascular disorder including aneurysmal formation (Fig. 2). The right VA was thicker than the left VA without any wall irregularity, and the BA was fully visualized on right vertebral angiography. $\mathrm{T}_{1}$-weighted sagittal magnetic resonance (MR) imaging on July 2 demonstrated an interpeduncular clot and a linear high signal intensity running parallel with the flow void of the BA. There was continuity between this clot and the linear high signal intensity (Fig. 3). Repeat vertebral angiography on July 3 revealed more marked wall irregularities of the left VA and the lower part of the BA, but did not visualize the distal BA. Based on these findings, left VA and BA dissecting aneurysm with a rupture site at the top of the BA was diagnosed, although angiography did not reveal the site of the arterial dissection.

The VA and lower BA were directly approached via a left suboccipital craniectomy on July 4 . An old 

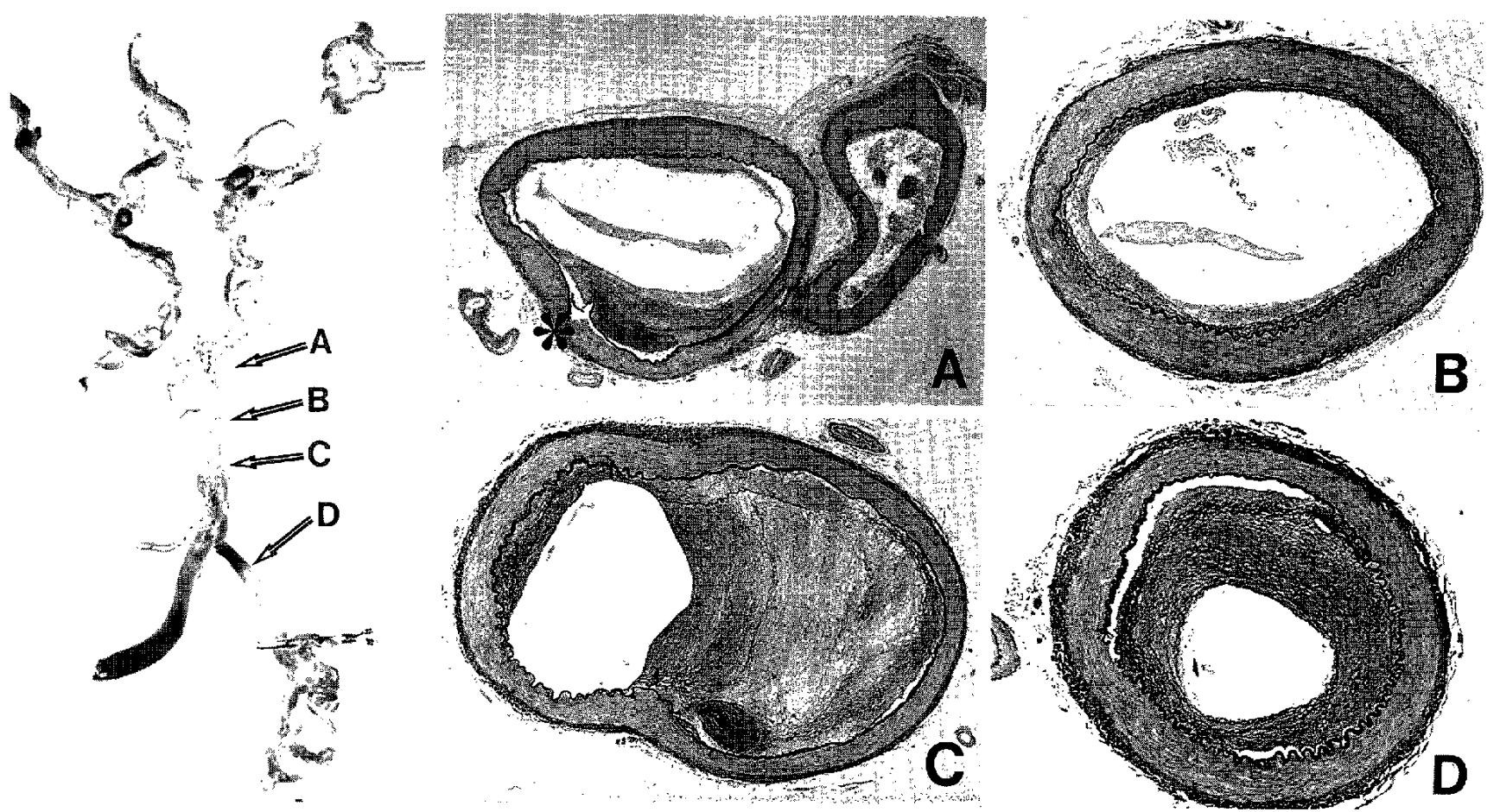

Fig. 4 Photomicrographs of four portions of the vertebrobasilar artery system revealing wall disruption (asterisk) at the top of the basilar artery (A), thin subintimal hemorrhage at the middle portion of the basilar artery (B), and thick subintimal hemorrhage at the lower portion of basilar artery (C) and at the distal left vertebral artery (D).

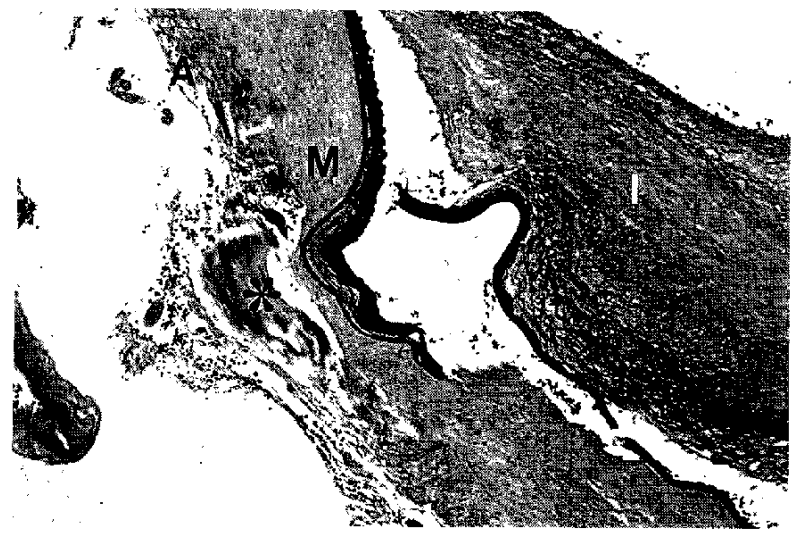

Fig. 5 Photomicrograph of the top of the basilar artery disclosing localized degenerative changes of three layers with destroyed elastic lamina and intramural old hemorrhage (asterisk) suspected to be the ruptured site, and thickened subintimal layer. No apparent connection was identified between this site and the subintimal changes of the basilar artery shown in the previous figure. A: adventitia, I: intima, M: media. HE stain, $\times \mathbf{4 0 0}$. remain obscure. ${ }^{2,3,6,14,18)}$ In our case, postmortem histological examination revealed an obvious disrupted change of the arterial wall associated with intramural hemorrhage was identified at the top of the $B A$. This site was completely congruous with the interpeduncular clot observed by CT and MR imaging, and macroscopically at autopsy. In addition, subintimal hemorrhage of the BA trunk was also identified but continuity to the disrupted site was unclear. As a result, this case was considered to be ruptured vertebrobasilar dissecting aneurysm.

On the other hand, CT findings of our case seems to belong to the category of perimesencephalic hemorrhage, although symptoms including loss of consciousness and dysphagia were not typical for perimesencephalic hemorrhage. Review of the causes of SAH of unknown origin suggested that the source of perimesencephalic hemorrhage may be rupture of a dilated vein or a venous malformation in the prepontine or interpeduncular cistern. However, the cause of this variant of SAH remains obscure. ${ }^{11)}$ Arterial dissection of the vertebrobasilar system such as in the present case may be one of the causes of perimesencephalic hemorrhage. 


\section{References}

1) Cioffi F, Pasqualin A, Cavazzani P, Da-Pian R: Subarachnoid hemorrhage of unknown origin: Clinical and tomographical aspect. Acta Neurochir (Wien) 97: 31-39, 1989

2) Endo $S$, Nishijima $M$, Nomura $H$, Takaku A, Okada E: A pathological study of intracranial posterior circulation dissecting aneurysms with subarachnoid hemorrhage: Report of three autopsied cases and review of the literature. Neurosurgery 33: 732-738, 1993

3) Farrel MA, Gilbert JJ, Kaufmann JC: Fatal intracranial dissection: Clinical pathological correlation. I Neurol Neurosurg Psychiatry 48: 111-121, 1985

4) Farres MT, Ferraz-Leite H, Schindler E, Muhlbauer M: Spontaneous subarachnoid hemorrhage with negative angiography: CT findings. J Comput Assist Tomogr 16: 534-537, 1992

5) Ferbert A, Hubo I, Biniek R: Non-traumatic subarachnoid hemorrhage with normal angiogram: Long-term follow-up and CT predictors of complications. J Neurol Sci 107: 14-18, 1992

6] Friedman AH, Drake CG: Subarachnoid hemorrhage from intracranial dissecting aneurysm. J Neurosurg 60: 325-334, 1984

7) Giombini S, Bruzzone MG, Pluchino F: Subarachnoid hemorrhage of unexplained cause. Neurosurgery 22: 313-316, 1988

8) Kassell NF, Torner JC, Jane JA, Haley EC Jr, Adams HP, participants: The international cooperative study on the timing of aneurysm surgery. Part 2: surgical results. J Neurosurg 73: 37-47, 1990

9) Kawamura S, Yasui N: Clinical and long-term followup study in patients with spontaneous subarachnoid hemorrhage of unknown aetiology. Acta Neurochir (Wien) 106: 110-114, 1990

10) Oder W, Kollegger H, Zeiler K, Dal-Bianco P, Wessely P, Deecke L: Subarachnoid hemorrhage of unknown etiology: Early prognostic factors for long-term func- tional capacity. J Neurosurg 74: 601-605, 1991

11) Rinkel GJE, Van-Gijn J, Wijdicks EFM: Subarachnoid hemorrhage without detectable aneurysm: A review of the courses. Stroke 24: 1403-1409, 1993

12) Rinkel GJE, Wijdicks EFM, Hasan D, Kienstra GEM, Franke CL, Hageman LM, Vermeulen M, Van-Gijn J: Outcome in patients with subarachnoid haemorrhage and negative angiography according to pattern of haemorrhage on computed tomography. Lancet 338: 964-968, 1991

13) Rinkel GJE, Wijdicks EFM, Vermeulen $M$, Hasan D, Brouwers PJAM, Van-Gijn J: The clinical course of perimesencephalic non-aneurysmal subarachnoid hemorrhage. Ann Neurol 29: 463-468, 1991

14) Rinkel GJE, Wijdicks EFM, Vermeulen $M$, Ramos LMP, Tanghe HLJ, Hasan D, Meiners LC, Van-Gijn J: Nonaneurysmal perimesencephalic subarachnoid hemorrhage: CT and MR patterns that differ from aneurysmal rupture. AJR Am J Roentgenol 157: 13251330, 1991

15) Sasaki O, Ogawa H, Koike T, Koizumi T, Tanaka R: A clinicopathological study of dissecting aneurysm of the intracranial vertebral artery. J Neurosurg 75: 874882, 1991

16) Van-Gijn J, Van-Dongen KJ, Vermulen $M$, Hijdra A: Perimesencephalic hemorrhage: A nonaneurysmal and benign form of subarachnoid hemorrhage. Neurology 35: 493-497, 1985

17) Yamaura A, Watanabe $Y$, Saeki N: Dissecting aneurysms of the intracranial vertebral artery. J Neurosurg 72: 183-188, 1990

18) Yonas H, Agamanolis D, Takaoka Y: Dissecting intracranial aneurysms. Surg Neurol 8: 407-415, 1977

Address reprint requests to: T. Ogiichi, M.D., Department of Neurosurgery, Toyama Medical and Pharmaceutical University, 2630 Sugitani, Toyama 930-01, Japan. 